\title{
The Detection performance of sensor on Corrosion electric Field of Ships
}

\author{
CHEN Fuyu ${ }^{1, a}$, LI Dingguo ${ }^{2, b}$, CHEN Cong ${ }^{3, c}$, FENG Yamin ${ }^{4, d}$ \\ 1,2,3,4 College of Sciences, Navy University of engineering, Wuhan 430033, Hubei, China \\ a chfuyu@163.com, ${ }^{b}$ Idg6407@163.com, ccckx7145@sohu.com, d13035136145@163.com
}

\begin{abstract}
Keywords: static electric fields; shaft-rate electric field of ships; $\mathrm{Ag} / \mathrm{AgCl}$ electrodes; performance test

Abstract. The corrosion of related electric field is an important exposure source of warships in sea water, the spread distance of low frequency part can be several kilometers in the sea water, which has a promising application prospects in aspects of remote detection and development of underwater weapon fuze. However, because the sea water has a strong attenuation effect on the electric field signal, it makes the low frequency signal of warships quite weak, the useful signals are often as low as $\mathrm{mV}$ level or even $\mu \mathrm{V}$ level. Therefore, it is of great significance to research on the low frequency weak signal detection sensor of warships. This paper selects the $\mathrm{Ag} / \mathrm{AgCl}$ electrode for performance test after comparing several electrodes, and the test results show that the $\mathrm{Ag} / \mathrm{AgCl}$ electrode has good performance on reversibility, Can respond to the change of electric field in time. The low frequency impedance of $\mathrm{Ag} / \mathrm{AgCl}$ electrode is small, and has good performance on on the electrochemical. $\mathrm{Ag} / \mathrm{AgCl}$ electrode has low self-noise at low frequency, the range potential changes at $0.3 \mathrm{mV}$ and the range fluctuation in 24 hours is less than $0.1 \mathrm{mV}$, which meets the detection requirements to low frequency weak electric field signal of warships.
\end{abstract}

\section{Introduction}

The source of relevant electric field of ship corrosion mainly has two aspects: the first aspect is that galvanic corrosion happens and electrochemical corrosion current generates when dissimilar metals in different parts of ship itself; the second aspect is that in order to restrain corrosion, ships adopt the system of sacrificial anode and impressed current cathodic protection and then anti-corrosion current generates. Both of them generate stronger electrostatic field in seawater, its frequency range is DC $\sim 0.5 \mathrm{~Hz}$. At the same time, corrosion and anti-corrosion current will generate extremely low-frequency alternating electric field with the frequency range of $1 \sim 7 \mathrm{~Hz}$ which is called shaft-rate electric field ${ }^{[1-3]}$ after the modulation of airscrew. Available literatures ${ }^{[4-7]}$ indicate the attenuation of low-frequency part of corrosion relevant electric field is smaller and its propagation distance can reach $5000 \mathrm{~m}$. Therefore, it has been an emphasis for various countries' navy to find target ships through measuring ships' low-frequency weak electric filed signals. American current equipped submarine underwater detection system has increased extremely low-frequency underwater electric field detection module ${ }^{[8]}$.

The difficulty in detecting underwater extremely low-frequency electric field is great and it has put forward many demands on performance of electrode:

(1) Seawater has strong attenuation on electric field signal, making the signal of underwater electric field weaker than that of electric field on land. After more than one or two times of hull length, useful signals usually reduce to $\mathrm{mV}$ even $\mu \mathrm{V}$, thus it needs electrode to have very high measuring sensitivity;

(2) When measuring, electrodes directly touch seawater and part of wires need to isolate from seawater, thus it needs electrodes to have good leakproofness;

(3) The depth range of exploring electrode laid in seabed is about $100 \sim 300 \mathrm{~m}$, and along with the increase in depth, the pressure will increase $1000 \mathrm{~Pa} / \mathrm{m}$, thus it needs electrodes to have certain resistance to pressure;

(4)Because of long-time work in seawater, microorganisms in marine environment will adhere 
to the surface of electrodes, thus it needs electrodes to have the function to restrain the growth of microorganisms.

$\mathrm{Ag} / \mathrm{AgCl}$ electrode is non-polarized electrode with fast reaction speed, strong ability to depolarize, relatively stable electrode potential, small polarization resistance and relatively low self noise of electrode. $\mathrm{AgCl}$ has certain inhibiting effect on the growth of marine organisms and its technology is comparatively mature, thus $\mathrm{Ag} / \mathrm{AgCl}$ electrode becomes most common sensitive elements of sensor for the measurement of underwater electric field. The following article chooses four all-solid-state $\mathrm{Ag} / \mathrm{AgCl}$ electrodes and tests their relevant performance in laboratory.

\section{Performance test of $\mathrm{Ag} / \mathrm{AgCl}$ electrode}

This article chooses 4 powder-forming types of all-solid-state $\mathrm{Ag} / \mathrm{AgCl}$ electrodes for performance test. The diameter of electrode is $1 \mathrm{~cm}$; the height is $1 \mathrm{~cm}$ and the serial number is $1,2,3$, and 4 . Design experiment: (1) adopt cyclic voltammetry to test the reversibility of $\mathrm{Ag} / \mathrm{AgCl}$ electrodes on signal response of electric field; (2) measure alternating current impedance (EIS) of electrode and represent electrochemical performance of electrode; (3) form electrode couple2-1, 3-1 and 4-1 and respectively test the self noise and short-term range stability of 24 hours of the three electrode couples.

\subsection{Reversibility test of signal response of electrode}

The reversibility of electrode on extremely low-frequency signal under marine environment decides whether electrode can really and timely respond to the changes of electric field under marine environment.

Adopt three-electrode system in which working electrode and reference electrode are solid-state $\mathrm{Ag} / \mathrm{AgCl}$ electrodes, and counter electrode is platinum electrode and use electrochemical workstation and cyclic voltammetry to measure the reversibility of solid-state $\mathrm{Ag} / \mathrm{AgCl}$ electrode on signal response of electric field, and the voltage variation range is $[-100 \mathrm{mV}, 100 \mathrm{mV}]$ and scanning speed is $1 \mathrm{mV} / \mathrm{s}$. The experimental result is shown as Fig 1. It can be seen the reversibility of the four electrodes is comparatively good, and during the on-load voltage range, the forward polarization curve and reverse polarization curve of the four electrodes basically coincide and present a good linear relation, which states the reversibility of solid-state $\mathrm{Ag} / \mathrm{AgCl}$ electrode is comparatively good and can timely and accurately reflect changes of electric field.

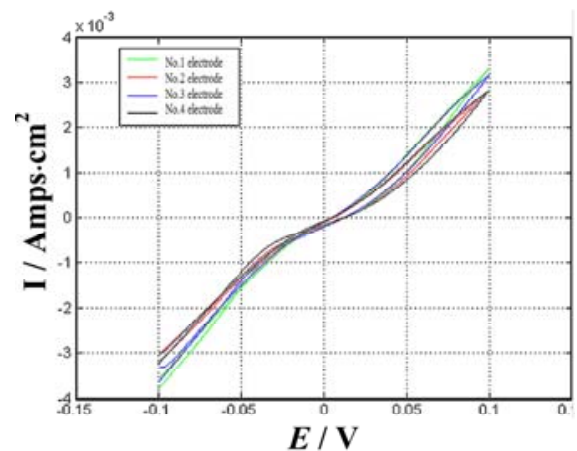

Fig 1. reversibility test of electrode

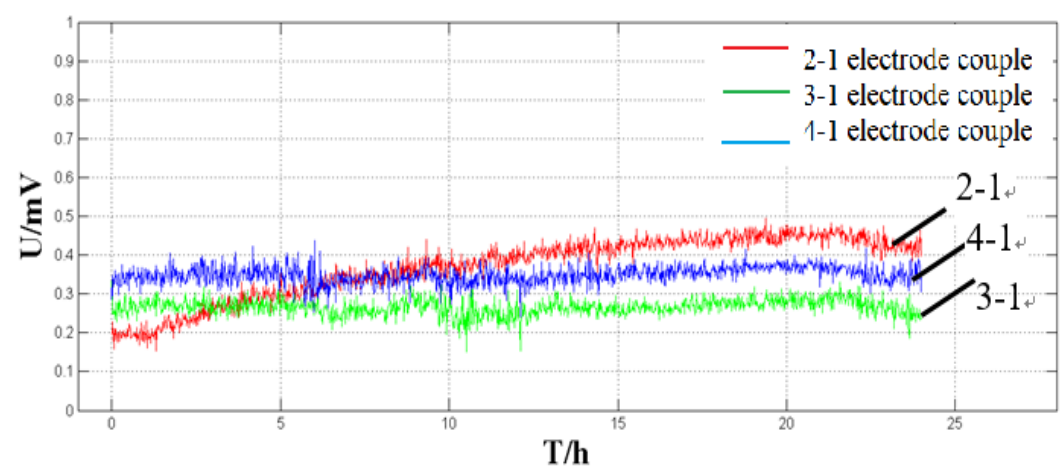

Fig 2. stability of electrode couple's range 24-hour range

\subsection{Stability test of electrode couple 24-hour range}

Seawater generates certain attenuation on underwater electric field signal of ships, thus making measurement signal very weak. Generally demand electrode range of the two electrodes is less than 1 $\mathrm{mV}$, and only in that way can weak signal not be submerged into the electrode potential drifting of electrode itself, and the measuring sensitivity is high.

Fig. 2 is 24 -hour range potential curve of the three couples of electrode during the measurement 
of 24 hours in $3.5 \% \mathrm{Na} \mathrm{Cl}$ solution. From the Fig., we can see after putting three groups of electrode couple into $3.5 \% \mathrm{Na} \mathrm{Cl}$ solution, range potential of the three electrode couples fluctuates above $0.3 \mathrm{mv}$, and among the three electrode couples, $2-1$ electrode couple's lower limit of fluctuation is $0.1542 \mathrm{mV}$ and its upper limit of fluctuation is $0.4958 \mathrm{mV}$, and this electrode couple's whole fluctuation is comparatively great and its 24-hour range numerical value is $0.3416 \mathrm{mV}$; 3 -1 electrode couple's lower limit of fluctuation is $0.2496 \mathrm{mV}$ and its upper limit of fluctuation is $0.3340 \mathrm{mV}$, and its 24-hour range numerical value is $0.0826 \mathrm{mV}$; 4-1electrode couple's lower limit of fluctuation is $0.3384 \mathrm{mV}$ and its upper limit of fluctuation is $0.4364 \mathrm{mV}$, and its 24-hour range numerical value is $0.098 \mathrm{mV}$. It can be seen that all the three groups of electrode couples satisfy the demand that electrode range is less than $1 \mathrm{mV}$, and among the three electrode couples, 3-1 and 4-1 electrode couple satisfy the demand that 24-hour range drifting is less than $0.1 \mathrm{mV}$.

\subsection{Alternating current impedance test of electrode}

Adopt three-electrode system in which working electrode and reference electrode are solid-state $\mathrm{Ag} / \mathrm{AgCl}$ electrodes, and counter electrode is platinum electrode and use electrochemical workstation to research alternating current impedance of electrode. Utilize Zsimpwin fitting software to fit data of alternating current impedance and fitting electric circuit chooses R (QR) according to experimental system. Atlases of the four electrodes' alternating current impedance are similar, so here we only choose Nyquist and Bode figure. of Number 2 electrode to analyze. From the Fig. 3, we can know the imitative effect of adopting $\mathrm{R}(\mathrm{QR})$ electric circuit is better, and the module value of impedance of electrode presents the tendency of gently declining in the frequency band of under $10 \mathrm{~Hz}$ and resistance value is about $100 \mathrm{Ohm}$, which indicates the electrochemical reaction performance of solid-state $\mathrm{Ag} / \mathrm{AgCl}$ electrode is relatively good and it can be applied to experiments at sea.

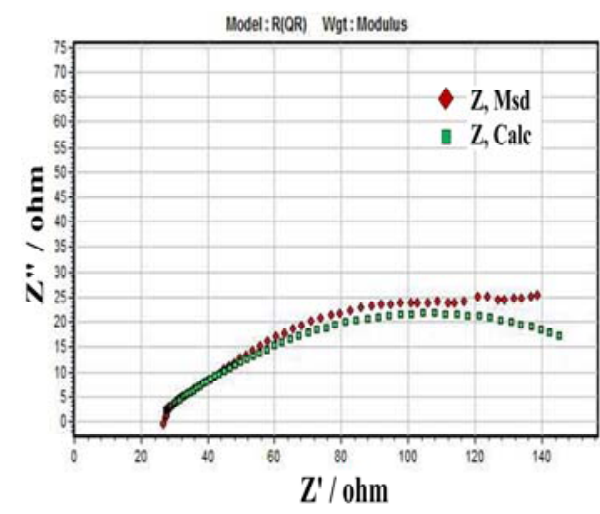

(a) Nyquist figure

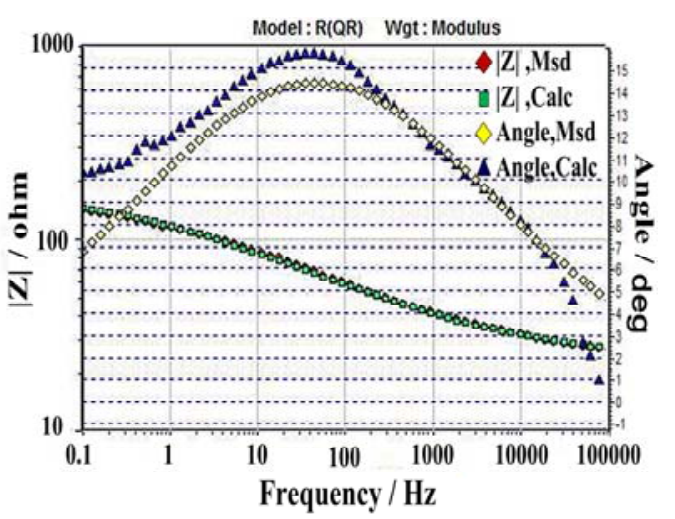

(b) Bode figure

Fig 3. alternating current impedance test of

\subsection{Self noise test of electrode couple}

The level of self noise is a very important parameter index to evaluate the performance of exploring electrode. Generally adopt $1 \mathrm{~Hz}$ bandwidth power spectrum root-mean-square noise to evaluate the self noise of electrode couple.

Put each electrode coupe into $3.5 \% \mathrm{NaCl}$ solution with the temperature of $6.8{ }^{\circ} \mathrm{C}$ and conductivity of $3.42 \mathrm{~S} / \mathrm{m}$, and then put them into shielding box and use electrochemical workstation to detect self noise of each electrode couple. Fig. 4 is the power spectrum chart of the three electrode couples on self noise test and from the Fig., we can see under the level of $1 \mathrm{~Hz}$ self noise, all the three groups of $\mathrm{Ag} / \mathrm{AgCl}$ electrode couple is in the magnitude of $10^{-14} \mathrm{~V}^{2} / \mathrm{Hz}$, and within the scope of DC $\sim 10 \mathrm{~Hz}$ whole extremely low-frequency frequency, the self noise of the three electrode couples maintain the magnitude from $10^{-12}$ to $10^{-15} \mathrm{~V}^{2} / \mathrm{Hz}$, and the self noise is lower, which can satisfy the demand of detecting low-frequency electric field. 


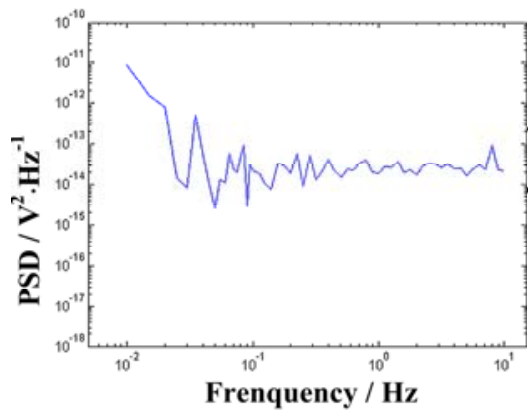

(a) 2-1 electrode couple

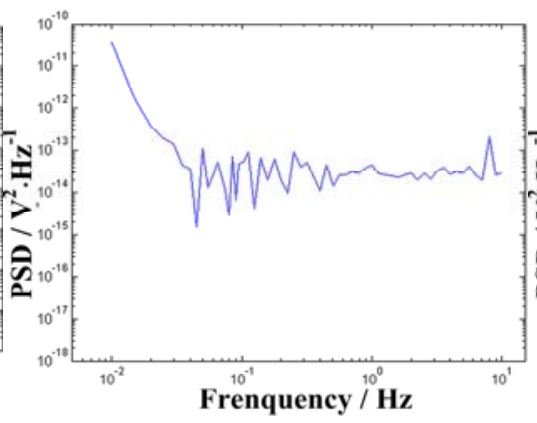

(b) 3-1 electrode couple

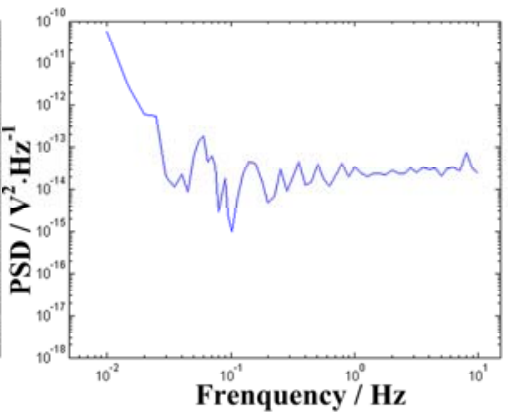

(c) 4-1 electrode couple

Fig 4. self noise of electrode couple

\section{Conclusions}

This article analyzes mechanism of production of corrosion relevant electrostatic field and shaft-rate electric field, propagation characteristics and application prospect, introduces the difficulties and matters needing attention in the aspect of underwater electric field detection in detail and researches solid-state electrode's reversibility, alternating current impedance, self noise and electrode range potential through experiments. Test results indicate chosen $\mathrm{Ag} / \mathrm{AgCl}$ electrode has better reversibility and can timely reflect changes in electric field in seawater; module value of alternating current impedance of electrode in low-frequency stage is about $100 \mathrm{Ohm}$, and as the frequency rises, it presents the tendency of slowly declining and the performance of electrochemical reaction is good; in extremely low-frequency stage, electrode has lower self noise and in DC $\sim 10 \mathrm{~Hz}$ frequency band, the level of self noise maintains the magnitude from $10^{-12}$ to $10^{-15} \mathrm{~V}^{2} / \mathrm{Hz}$; the electrode range potential is relatively small and about $0.3 \mathrm{mV}$, and during 24 hours, the fluctuation of electrode range is less than $0.1 \mathrm{mV}$, and it has better short-term stability. Analysis and experiment show $\mathrm{Ag} / \mathrm{AgCl}$ electrode satisfies the demand of detecting low-frequency signal of relevant electric field of ship corrosion.

\section{References}

[1] Cong Chen, Dingguo Li, Zhiguo Jiang,et al. Electric field of a static electric dipole in three-layer medium model usingsecondary equivalent method[J]. Acta Physica Sinica,2012,61( 24) : 244101

[2] Hao Tan, Yizhuo Jia, Shenguang Gong. Real-time detection of shaft-rate electric field of ships based on R BF neuralnetwork regressive prediction[J]. Journal of Basic Science and Engineering,2013,21( 1) : 167-173.

[3] Birsan M. Measurement of the extremely low frequency (ELF) magnetic field emission from a ship[J]. Measurement Science and Technology, 2011, 22(8): 085709.

[4] Marius B. Measurement of the extremely low frequency (ELF) magnetic field emission from a ship[J]. Measurement science and technology,2011,22(8):085709-85717.

[5] Hill D A, Wait J R. Excitation of the Zenneck surface wave by a vertical aperture[J]. Radio Science, 1978, 13(6): 969-977.

[6] Pan W Y, Zhang H Q. Electromagnetic field of a vertical electric dipole on the spherical conductor covered with a dielectric layer[J]. Radio Science, 2003, 38(3).

[7] Liu L, Li K. Radiation from a vertical electric dipole in the presence of a three-layered region[J]. Antennas and Propagation, IEEE Transactions on, 2007, 55(12): 3469-3475.

[8] Lu Xiong. On the Mathematic modeling of submarine Shaft-rate Electric Field[D]. Wuhan. Naval University of Engineering; 